\title{
Quantitative Survey of 3-alkyl-2-methoxypyrazines and First Confirmation of 3-ethyl-2-methoxypyrazine in South African Sauvignon blanc Wines
}

\author{
P. Alberts ${ }^{1,2}$, M. Kidd ${ }^{3}$, M.A. Stander ${ }^{4}$, H.H. Nieuwoudt ${ }^{5}$, A.G.J. Tredoux ${ }^{5}$, A. de Villiers ${ }^{1 *}$
}

(1) Department of Chemistry and Polymer Science, Stellenbosch University, Private Bag X1, Matieland, 7602, South Africa

(2) Department of Agriculture, Forestry and Fisheries, Private Bag X5015, Stellenbosch, 7599, South Africa

(3) Statistics and Actuarial Science, Centre for Statistical Consultation, Stellenbosch University, Private Bag X1, Matieland 7602, Stellenbosch, South Africa

(4) Department of Biochemistry, Stellenbosch University, Private Bag X1, Matieland, 7602, South Africa

(5) Institute for Wine Biotechnology, Stellenbosch University, Private Bag X1, Matieland, 7602, South Africa

Submitted for publication: October 2012

Accepted for publication: January 2013

Key words: Sauvignon blanc wine, liquid chromatography-tandem mass spectrometry, 3-alkyl-2-methoxypyrazines, 3-ethyl2-methoxypyrazine

\begin{abstract}
3-Alkyl-2-methoxypyrazines are important aroma components in Sauvignon blanc wine, contributing to the typical vegetative character associated with the cultivar. The analysis of methoxypyrazines is highly challenging and, as a result, limited quantitative data are available for South African Sauvignon blanc wines. In this study, liquid chromatography-tandem mass spectrometry was applied for the sensitive quantification of the three principal methoxypyrazines in 881 South African Sauvignon blanc wines. The total wine methoxypyrazine concentration exceeded the combined recognition threshold for the vegetative aroma in more than $60 \%$ of the samples, demonstrating the involvement of these compounds in the typical aroma of the cultivar. The analytical method was adapted to allow the accurate quantitation and spectral confirmation of 3-ethyl-2-methoxypyrazine in Sauvignon blanc wines for the first time. Concentrations ranged between 1.1 and $4.9 \mathrm{ng} / \mathrm{L}$. Statistically significant relationships between wine methoxypyrazine concentrations and parameters related to the maturity of the grapes and to the climate, as well as geographical origin and vintage, were found.
\end{abstract}

\section{INTRODUCTION}

Sauvignon blanc is a distinctive dry white wine with a characteristic aroma described as nuances of vegetative, herbaceous and green pepper. Three 3-alkyl-2-methoxypyrazines (MPs), namely 3-isobutylmethoxypyrazine (IBMP), 3-sec-butyl-methoxypyrazine (SBMP) and 3-isopropyl-2-methoxypyrazine (IPMP), are principally responsible for the distinctive vegetal character of the cultivar (Lacey et al., 1991; Allen \& Lacey, 1998; Roujou de Boubee et al., 2000; Sala et al., 2002; Marais, 2004; Marais et al., 2004). These grape-derived flavour components have extremely low sensory detection thresholds (Table 1). Some congeners influence the aroma of white wine at concentrations of $1 \mathrm{ng} / \mathrm{L}$ to $2 \mathrm{ng} / \mathrm{L}$, while their detection threshold in red wine is $10 \mathrm{ng} / \mathrm{L}$ to $15 \mathrm{ng} / \mathrm{L}$ (Allen \& Lacey, 1998; Roujou de Boubee et al., 2000; Marais et al., 2004). In wine, MPs typically occur at trace level amounts, with a combined concentration that is in the order of $1 \mathrm{ng} / \mathrm{L}$ to 40 ng/L (Allen \& Lacey, 1998).
IBMP is invariably the most abundant congener found in Sauvignon blanc wine, representing approximately $80 \%$ of the total, while IPMP and SBMP occur in roughly equal amounts (Allen et al., 1991; Marais et al., 2004; Alberts et al., 2009). The occurrence of 3-ethyl-2-methoxypyrazine (EMP) in wine has also been reported tentatively (Augustyn et al., 1982; Allen \& Lacey, 1998; Sala et al., 2000, 2002), while the possible occurrence of 3-methyl-2-methoxypyrazine (MMP) has been suggested on the basis of a feasible biosynthetic route (Lacey et al., 1991). These latter pyrazines are associated with "earthy" aromas and have relatively high olfactory detection thresholds (Table 1); they therefore are unlikely to contribute significantly to the typical "green" Sauvignon blanc wine aroma. Sala et al. $(2000,2002)$ reported the presence of EMP in Merlot and Cabernet Sauvignon musts and wines, but found concentrations that were consistently below the quantification level of their analytical methods $(0.5 \mathrm{ng} / \mathrm{L}$ to $4 \mathrm{ng} / \mathrm{L})$. In a preliminary investigation, Allen and Lacey (1998) reported levels of EMP as high as 1000

*Corresponding author: E-mail: ajdevill@sun.ac.za [Tel.: +27 21808 3351; Fax: +27 21808 3360] 
TABLE 1

Chemical structures, odour thresholds and flavour properties of the principal 3-alkyl-2-methoxypyrazines found in wine.

\begin{tabular}{|c|c|c|c|}
\hline Compound & Structure & $\begin{array}{l}\text { Odour threshold } \\
\text { in water }(\mathrm{ng} / \mathrm{L})^{\mathrm{a}}\end{array}$ & Flavour description ${ }^{b}$ \\
\hline IBMP & & $1-2$ & Bell peppers \\
\hline IPMP & & $1-2$ & Bell peppers, green peas \\
\hline SBMP & & $1-2$ & Galbanum, ivy leaves, green peas \\
\hline EMP & & 425 & Raw potato \\
\hline MMP & & 4000 & Roasted peanuts \\
\hline
\end{tabular}

${ }^{a}$ Allen et al., 1998, Maga et al., 1973

${ }^{\mathrm{b}}$ Maga et al., 1973, Murray et al., 1975

$\mathrm{ng} / \mathrm{L}$ in a Cabernet Sauvignon wine, as well as more than $100 \mathrm{ng} / \mathrm{L}$ in a Pinot noir wine. However, there is limited information available pertaining to the occurrence of this compound in grapes and wines of different cultivars. Apart from the single tentative report by Allen and Lacey (1998), who found unusually high levels of EMP, no quantitative data on EMP have been reported. This lack of information is largely due to the challenges associated with the analysis of these trace level compounds in the complex wine matrix (Schmarr et al., 2010).

In grapes, the concentrations of MPs are strongly influenced by climatic and viticultural conditions, and generally decrease after véraison (Allen \& Lacey, 1998; Roujou de Boubee et al., 2000; Marais et al., 2004). In addition, oenological factors also affect wine MP levels. As a consequence, Sauvignon blanc wine possessing the typical green pepper or vegetative aroma is sensitive to production factors such as geographical origin (Lacey et al., 1991; Marais et al., 1999), mesoclimatic conditions (Lacey et al., 1991; Marais et al., 1999; Falcăo et al., 2007), canopy microclimate (Marais et al., 1999; Sala et al., 2005), water availability (Sala et al., 2005), solar radiation (Hashizume \& Samuta et al., 1999; Sala et al., 2004) and time of harvesting (Ryona et al., 2010). Marais et al. (1999) reported that canopy microclimate plays a particularly important role in determining grape MP levels and that exposure to solar radiation, as manipulated by canopy management, has a more prominent effect than climatic temperature alone. Viticultural practices (Marais et al., 1999; Maggu et al., 2007) and the yeast strain used (Pickering et al., 2008) also affect wine MP concentrations. Moreover, possible infestations with lady beetles may also contribute MPs to affected wines. In particular, elevated levels of IPMP and SBMP are associated with this phenomenon (Galvan et al., 2008). It has also been reported that bottle closure and packaging type affect MP concentrations during wine storage, with the three major MPs affected to differing degrees. Some closure and packaging types even lead to increases in wine IPMP and SBMP concentrations (Blake et al., 2009). This sensitivity of MP levels to oenological, production and ageing variables possibly contributes to the observed variance in their occurrence in Sauvignon blanc wine.

We have previously reported a survey on MP levels in South African Sauvignon blanc wines and found levels of IBMP ranging from 0.40 to $44 \mathrm{ng} / \mathrm{L}$ (RSD of $102 \%$ ) in 577 wines, while concentrations of IPMP and SBMP ranged from $<0.03$ to $3.9 \mathrm{ng} / \mathrm{L}$ and $<0.03$ to $3.2 \mathrm{ng} / \mathrm{L}$ respectively (Alberts et al., 2009). In the current study, 304 additional Sauvignon blanc wines were analysed. Data representing a broader span of vintages and origins were obtained with 
the aim of improving the statistical representation of the South African Sauvignon blanc industry in order to allow closer investigation of trends in the data. Malic acid levels were also determined for a subset of samples, since malic acid concentration is strongly influenced by viniviticultural variables and therefore can reveal information pertaining to the climate of cultivation and the maturity of the grapes. Malic acid concentration was used together with general wine parameters, such as $\mathrm{pH}$, alcohol content (Alc), total acidity (TA) and volatile acidity (VA), in an attempt to identify the factors that are responsible for the production of varietal-typical Sauvignon blanc wines possessing the vegetative aroma.

Moreover, given the limited information on MMP and EMP levels in Sauvignon blanc wines, the liquid chromatography-tandem mass spectrometry (LC-MS/MS) method that was previously reported (Alberts et al., 2009) was adapted to yield firm spectral information for the confirmation of the presence of EMP in these wines, as well as quantitative data on this compound in South African wines for the first time. This method utilises advantages inherent to LC-MS/MS to obtain very low detection limits.

\section{MATERIALS AND METHODS}

\section{Chemicals and standards}

High-purity chemicals and solvents were used throughout. Methanol, ethyl acetate, MMP, EMP, IPMP, IBMP and SBMP were obtained from Sigma-Aldrich (Mulbarton, South Africa); formic acid, malic acid, phosphoric acid and tannic acid were obtained from Saarchem (Wadeville, South Africa); while acetonitrile, dichloromethane and hexane were obtained from Burdick \& Jackson (Honeywell International, Muskegon, USA).

Standards were prepared by weighing an appropriate amount of reference material on an analytical balance. All dilutions were made using A-grade glassware. Standards were prepared in a solution of $40 \%$ acetonitrile. Wine samples for the recovery study were fortified volumetrically by adding appropriate amounts of working standards.

\section{Samples}

A total of 881 South African Sauvignon blanc wines, from all wine-producing regions and of vintages 1999 to 2011, were analysed. The vintage distribution of these samples was as follows (number of samples in parenthesis) 1999 (1), 2000 (1), 2001 (1), 2002 (12), 2003 (56), 2004 (199), 2005 (308), 2006 (58), 2007 (54), 2008 (109), 2009 (49), 2010 (15) and 2011 (18). Samples were obtained from submissions under the South African controlled appellations system (South African Wine and Spirit Board), as well as from export applications (South African National Department of Agriculture). General wine parameters such as $\mathrm{pH}$, alcohol content, total acids and volatile acids were obtained from archived data that were used for the certification of these products under the South African controlled appellations system. Malic acid concentrations were determined for a subset $(n=158)$ of Sauvignon blanc wine samples using a liquid chromatography-ultraviolet detection (LC-UV) method as outlined below.

\section{Sample preparation}

\section{Extraction of MPs for quantitative analysis}

The procedure used for the analysis of MPs has been described previously (Alberts et al., 2009). Briefly, $500 \mathrm{~mL}$ wine was distilled utilising a $60 \mathrm{~cm}$ fractionating column, and the first $100 \mathrm{~mL}$ of distillate was collected. The distillate was then extracted exhaustively with dichloromethane $(10 \mathrm{~mL}, 5 \mathrm{~mL}$ and $5 \mathrm{~mL}$, respectively). The combined dichloromethane fractions were acidified and concentrated by evaporation. Finally, the extract was reconstituted to $1 \mathrm{~mL}$ with a solution of $40 \%$ acetonitrile in water, homogenised, and transferred to a $1.8 \mathrm{~mL}$ vial for analysis.

\section{Extraction of MMP and EMP for qualitative analysis}

For spectral identification of MMP and EMP in the Sauvignon blanc extracts, further semi-quantitative concentration and purification were performed using the following procedure. Approximately $0.9 \mathrm{~mL}$ of extract was removed from the autosampler vial and transferred to a $5 \mathrm{~mL}$ test tube. A $1 \mathrm{~mL}$ aliquot of hexane was added, followed by extraction on a vortex mixer at high speed for one minute. The hexane phase was then drawn off and transferred to a $5 \mathrm{~mL}$ test tube containing $1 \mathrm{~mL}$ of $10 \%$ formic acid in ethyl acetate. This solution was homogenised on a vortex mixer and evaporated under a gentle stream of nitrogen at room temperature to a volume of $<100 \mu \mathrm{L}$. This residue was then redissolved in $200 \mu \mathrm{L}$ of a solution of $50 \%$ acetonitrile in water. If required, acetonitrile was added drop-wise until a homogeneous solution was obtained following high-speed vortex mixing. Finally, the solution ( $\mathrm{ca} .300 \mu \mathrm{L}$ ) was transferred to a totalrecovery autosampler vial for analysis.

\section{Chromatographic details \\ LC-MS/MS methods for the determination of MPS Quantitative analysis of MPS (HPLC program A)}

Chromatographic analysis was performed as reported previously (Alberts et al., 2009), using a Waters Alliance 2695 liquid chromatograph (Waters Corporation, Milford, U.S.A.) coupled to a Micromass Quattro Premier XE tandem quadrupole mass spectrometric detector (Micromass Limited, Manchester, U.K.). Chromatographic separation was in reversed phase mode, employing a methanol and water gradient and a phenyl hexyl column (Phenomenex Luna, Torrance, U.S.A.) with dimensions 250 x $4.6 \mathrm{~mm}$ (3 $\mu \mathrm{m}$ particle size), thermostatted at $40^{\circ} \mathrm{C}$. The gradient started at $35 \%$ methanol and increased to $80 \%$ in $18 \mathrm{~min}$, followed by column clean-up ( $95 \%$ methanol for $2.4 \mathrm{~min}$ ) and re-equilibration. The flow rate was $1 \mathrm{~mL} / \mathrm{min}$ and the total runtime $25 \mathrm{~min}$. This HPLC method is designated Program $\mathrm{A}$ in the following discussions. A divert valve was used to direct the column effluent to the detector only between time 9.4 and $20.4 \mathrm{~min}$, the rest being vented to waste. Variable injection volumes were used, with the maximum injection volume being limited to $100 \mu \mathrm{L}$. Ionisation was performed in positive ion mode with atmospheric pressure chemical ionisation (APCI). The corona current was $4.4 \mu \mathrm{A}$, cone voltage $34 \mathrm{~V}$, and source and desolvation temperatures 150 and $200^{\circ} \mathrm{C}$ respectively. The mass spectrometer was operated in multiple reaction monitoring (MRM) mode, acquiring data for at least two ion transitions per analyte. Compounds 
were identified using retention times as well as ion ratios (Table 2).

Qualitative analysis of EMP (HPLC program B)

For qualitative confirmation of EMP and MMP, sample extracts for quantitative analysis were further purified and concentrated as described above. The method for these analyses was identical to the one described above, except that the gradient separation was performed between 25 to $65 \%$ methanol and an injection volume of $10 \mu \mathrm{L}$ was used. Only EMP and MMP were then eluted in the mass spectral acquisition window to obtain critical separation of the target compounds from interfering peaks. In order to distinguish this procedure from the one described above that is used to separate five MPs, it will be designated HPLC Program B in the following discussion.

\section{LC-UV method for the determination of malic acid}

Malic acid was determined by direct injection ion chromatography with UV detection. An Agilent 1100 LC system (Agilent Technologies, Waldbronn, Germany) fitted with a quaternary pump, autosampler, column oven and UV-visible diode array detector was used. Chromatographic separation was performed in ion exchange mode using a sulphonated (sulphonic acid form) styrene divinyl benzene-based column (Phenomenex, Torrance, U.S.A.) of dimensions $300 \times 7.8 \mathrm{~mm}(8 \mu \mathrm{m}$ particle size $)$. The mobile phase was $0.05 \%(\mathrm{v} / \mathrm{v})$ phosphoric acid in water. The column was thermostatted at $80^{\circ} \mathrm{C}$ and the flow rate was $0.9 \mathrm{~mL} / \mathrm{min}$. The runtime was $20 \mathrm{~min}$ and injection volumes of $0.1 \mu \mathrm{L}$ were used, while the chromatographic signal was recorded at $210 \mathrm{~nm}$.

\section{Data analysis and statistical methods}

Factor analysis and ANOVA were performed utilising Statistica (version 10, StatSoft, Inc., Tulsa, OK, USA) software. Pearson correlation coefficients were used to determine relationships between wine parameters and total methoxypyrazine concentration. Factor analysis was used to further investigate correlation structures between variables and possible latent structures underlying the data. Parallel analysis was used to determine the number of factors. Main effects ANOVA was used to test for differences in total methoxypyrazine between regions and districts, taking vintage into account. Due to the non-normal nature of the data, log transformations were used.

\section{RESULTS AND DISCUSSION}

\section{Performance and validation of the LC-APCI-MS/MS procedure}

The LC-MS/MS method for the determination of methoxypyrazines in Sauvignon blanc wine used in this study is based on a procedure that was developed previously for this purpose (Alberts et al., 2009). The method combines the loading capacity inherent to LC with the sensitivity and selectivity of MS/MS in MRM mode, as well as highly concentrated extracts, to achieve very low limits of detection (LODs). The scope of the method reported previously was extended by the addition of MMP and EMP as target analytes (HPLC program A, Chromatographic details).

The system response was linear $\left(\mathrm{r}^{2} \mathrm{ca}\right.$. 0.9999) for calibration standards over the range $c a .7 \mathrm{pg}$ to $20000 \mathrm{pg}$ oncolumn, corresponding to a maximum sample concentration of $400 \mathrm{ng} / \mathrm{L}$ (for a concentration factor of 500 and $100 \mu \mathrm{L}$ injection). The limits of detection (LOD) and limits of quantification (LOQ) for the three major MPs (IPMP, IBMP and SBMP) were $0.03 \mathrm{ng} / \mathrm{L}$ and $0.10 \mathrm{ng} / \mathrm{L}$ respectively. The LOD and LOQ for EMP were $0.10 \mathrm{ng} / \mathrm{L}$ and $0.33 \mathrm{ng} / \mathrm{L}$ respectively. Although $15 \mathrm{pg}$ (LOD of $0.33 \mathrm{ng} / \mathrm{L}$ ) MMP could be detected in a standard, the recovery study showed that, in real samples, the signal was obscured by co-eluting matrix components at that concentration. The quantification of MMP therefore only was reliable above levels of $10 \mathrm{ng} / \mathrm{L}$. Compound identification was achieved using retention times as well as the ion ratios for three MRM transitions (Table 2). Three ion transitions were recorded for EMP, namely $\mathrm{m} / \mathrm{z}$ 138.9 to $123.9,111.0$ and 83.0. For qualitative purposes, a tolerance of $2.5 \%$ in retention time and $20 \%$ in the ion ratios (relative to calibration standards) was used (O'Keeffe et al., 2003). Fig. 1 shows MRM chromatograms of four ion transitions used to quantify MPs in the extract of a Sauvignon blanc wine.

TABLE 2

MRM transitions and peak identification criteria used for the LC-APCI-MS/MS determination of 3-alkyl-2-methoxypyrazines (ion ratios given in parenthesis).

\begin{tabular}{|c|c|c|c|c|c|}
\hline Compound & $\begin{array}{l}\text { Retention } \\
\text { time (min) }\end{array}$ & $\begin{array}{l}\text { Target } \\
\text { ion (Da) }\end{array}$ & $\begin{array}{l}\text { Product } \\
\text { ion (Da) }\end{array}$ & $\begin{array}{l}\text { Transition } \\
\text { (ion ratio) }\end{array}$ & $\begin{array}{l}\text { Collision } \\
\text { energy }(\mathrm{eV})\end{array}$ \\
\hline \multirow[t]{2}{*}{ MMP } & 10.6 & 124.9 & 56.2 & $2^{\circ}(2.4)$ & 20 \\
\hline & & 124.9 & 97.0 & $1^{\circ}$ & 16 \\
\hline \multirow[t]{3}{*}{ EMP } & 13.8 & 138.9 & 111.0 & $3^{\circ}(3.4)$ & 16 \\
\hline & & 138.9 & 83.0 & $2^{\circ}(1.4)$ & 16 \\
\hline & & 138.9 & 123.9 & $1^{\circ}$ & 20 \\
\hline \multirow[t]{2}{*}{ IPMP } & 16.7 & 152.9 & 122.9 & $2^{\circ}(1.1)$ & 26 \\
\hline & & 152.9 & 137.9 & $1^{\circ}$ & 18 \\
\hline \multirow[t]{2}{*}{ IBMP } & 18.3 & 166.9 & 123.9 & $2^{\circ}(1.3)$ & 22 \\
\hline & & 166.9 & 124.9 & $1^{\circ}$ & 16 \\
\hline \multirow[t]{2}{*}{ SBMP } & 18.7 & 166.9 & 122.9 & $2^{\circ}(1.9)$ & 24 \\
\hline & & 166.9 & 137.9 & $1^{\circ}$ & 18 \\
\hline
\end{tabular}


The accuracy of the method was assessed as the recovery of MPs from samples of Sauvignon blanc wine suitably fortified prior to the sample preparation step. Six replicate sets of recovery measurements were made at three levels of fortification (1, 10 and $100 \mathrm{ng} / \mathrm{L})$. A complete summary of the results of the recovery study, including overall recovery over the range of levels investigated, is presented in Table 3.

The reproducibility of the LC-APCI-MS/MS instrument, expressed as the relative standard deviation (RSD) of the peak area obtained for a standard (IBMP), was better than $2 \%(n=8)$. The intra-assay precision, assessed as repeatability of the recovery, was better than $11 \%$ (expressed as RSD) at concentrations of $1 \mathrm{ng} / \mathrm{L}, 10 \mathrm{ng} / \mathrm{L}$ and 100 ng/L (IPMP, IBMP and SBMP only). The uncertainty of measurement associated with the procedure was estimated by calculating the range of the $95 \%$ confidence interval about the measurements performed in the recovery study (i.e. at levels of 1,10 and $100 \mathrm{ng} / \mathrm{L}$ ). Results are reported using the significant figure convention, according to which the result is reported by recording all the certain digits and the first uncertain digit (Skoog et al., 1996). As the limit of quantification of the procedure was determined to be a tenth of $1 \mathrm{ng} / \mathrm{L}$, and the recoveries of the order $85 \pm 5 \%$, all results are reported in units of $\mathrm{ng} / \mathrm{L}$, using two significant figures.

The accuracy of the LC-APCI-MS/MS method was confirmed by comparison of quantitative results for the same samples with those obtained by an independent laboratory utilising a validated solid phase micro-extraction GC-MS method. Due to lower of sensitivity of the GC method (LOQ $=5 \mathrm{ng} / \mathrm{L}$ ), only results for IBMP could be compared. Very good correlation was observed between these two sets of measurements $\left(r^{2}=0.986, n=6\right)$.

\section{Investigation of the occurrence of MMP and EMP in South African Sauvignon blanc wines}

To investigate the occurrence of MMP and EMP, a subset of 10 South African Sauvignon blanc wines was used. EMP was detected and quantified in these samples using the MRM chromatogram of the primary ion transition $(\mathrm{m} / \mathrm{z}$ 138.9 to 123.9 ) following analysis with HPLC program A. The secondary and tertiary ion transition peaks $(\mathrm{m} / z 138.9$ to 111.0 and 83.0 ) were obscured by co-eluting matrix elements so that firm spectral confirmation of the compound could not be obtained according to the criteria given in Table 2. MMP was not detected $(<10 \mathrm{ng} / \mathrm{L})$ in any of the wines analysed. However, since data pertaining to EMP in South African Sauvignon blanc wines are reported here for the first time, firm spectral compound identification was imperative. These extracts were therefore further purified as described under Sample preparation and subsequently

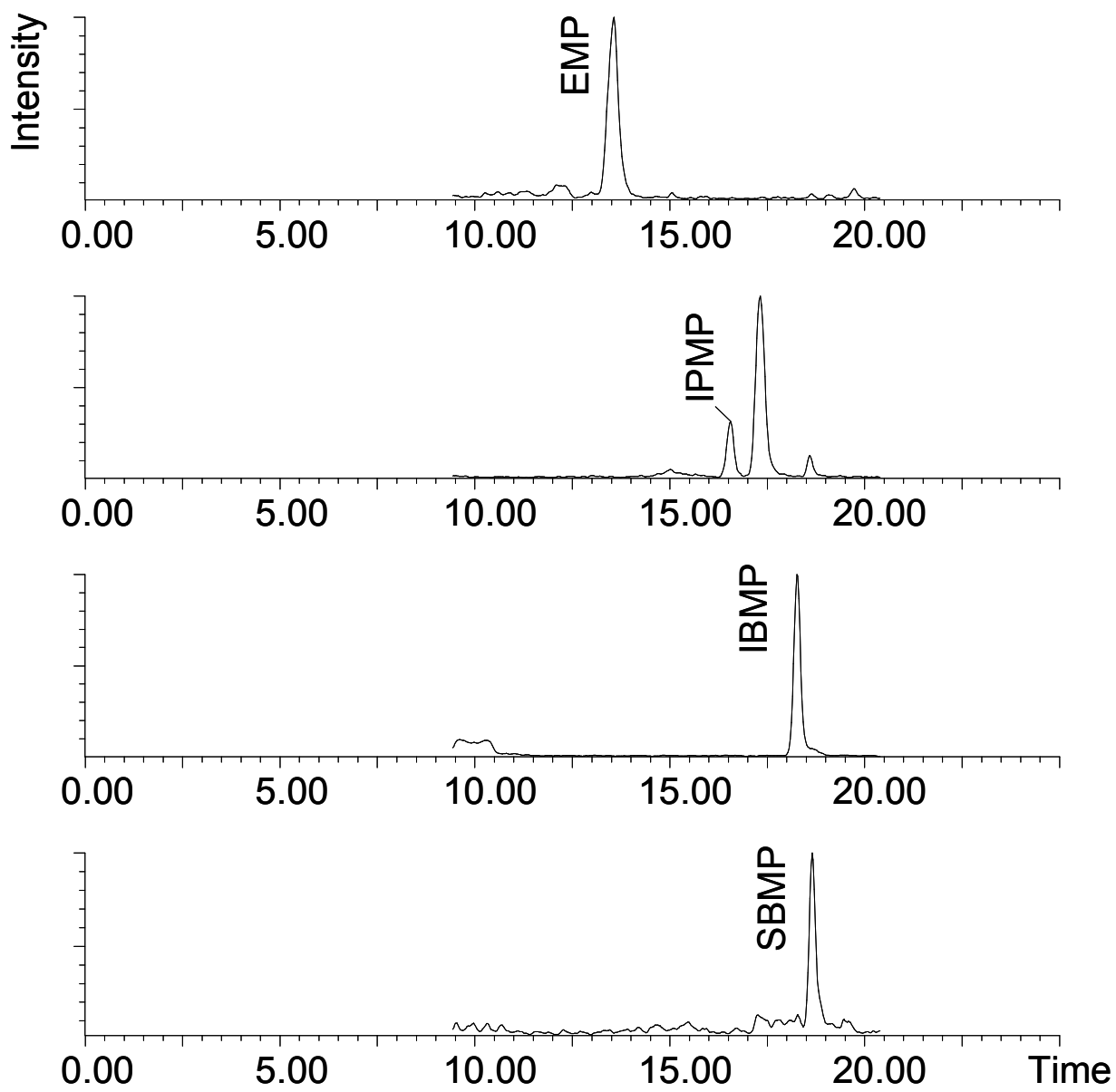

FIGURE 1

MRM chromatograms of four ion transitions used to quantify MPs in extracts of Sauvignon blanc wine. EMP (4.1 $\mu \mathrm{g} / \mathrm{L})$, IPMP $(0.54 \mu \mathrm{g} / \mathrm{L}), \operatorname{IBMP}(10 \mu \mathrm{g} / \mathrm{L}), \operatorname{SBMP}(0.62 \mu \mathrm{g} / \mathrm{L})$. The injection volume was $100 \mu \mathrm{L}$. 
re-analysed with a modified HPLC program (Program B, Chromatographic details) to positively identify EMP in these wines. This procedure involved selective back-extraction of the MPs from the concentrated extracts, which served to further enrich the MPs while reducing the interfering sample matrix. The presence of EMP in each sample was inferred unambiguously from the correlation of retention time, as well as two ion ratios for three ion transitions, compared with the reference standard. MRM chromatograms for three ion transitions obtained for the purified extract of a sample of
Sauvignon blanc wine are displayed in Fig. 2.

Augustyn et al. (1982) reported the first qualitative data for EMP in Sauvignon blanc wine. Allen and Lacey (1998) tentatively reported EMP concentrations of between 100 and $1000 \mathrm{ng} / \mathrm{L}$ for two red wines. The occurrence of MMP and EMP in wines was subsequently investigated by several further studies utilising headspace solid phase microextraction combined with GC and nitrogen-phosphorus selective detection (Sala et al., 2000, 2002) or tandem mass spectrometry (Godelmann et al., 2008), as well as liquid

TABLE 3

Average recovery of MPs at three levels of fortification (1, 10 and $100 \mathrm{ng} / \mathrm{L}$ ), as well as overall recovery (average recovery over all levels investigated). The relative standard deviation, as a percentage, is given in parenthesis.

\begin{tabular}{llllll}
\hline Recovery (\%) & MMP & EMP & IPMP & IBMP & SBMP \\
\hline $\mathbf{1 ~ n g / L ~}$ & $n=6$ & $n=6$ & $n=6$ & $n=6$ & $n=6$ \\
ave (\% RSD) & a $^{\mathrm{a}}$ & $90.8(28.2)$ & $81.6(10.3)$ & $95.0(11.3)$ & $96.8(5.0)$ \\
\hline $\mathbf{1 0} \mathbf{~ n g / L ~}$ & $n=6$ & $n=6$ & $n=6$ & $n=6$ & $n=6$ \\
ave (\% RSD) & $65.7(12.6)$ & $79.6(5.5)$ & $80.0(5.5)$ & $87.3(5.6)$ & $80.4(4.1)$ \\
\hline $\mathbf{1 0 0} \mathbf{~ n g / L}$ & $n=6$ & $n=6$ & $n=6$ & $n=6$ & $n=6$ \\
ave (\% RSD) & $62.8(6.9)$ & $78.1(4.2)$ & $79.9(5.1)$ & $87.7(3.2)$ & $80.6(3.4)$ \\
\hline Overall & $n=12$ & $n=18$ & $n=18$ & $n=18$ & $n=18$ \\
ave (\% RSD) & $64.3(10.2)$ & $82.8(18.6)$ & $80.5(7.0)$ & $90.0(8.4)$ & $85.9(10.1)$ \\
\hline
\end{tabular}

${ }^{\text {a }}$ MMP could not be accurately quantified at this concentration due to matrix interferences
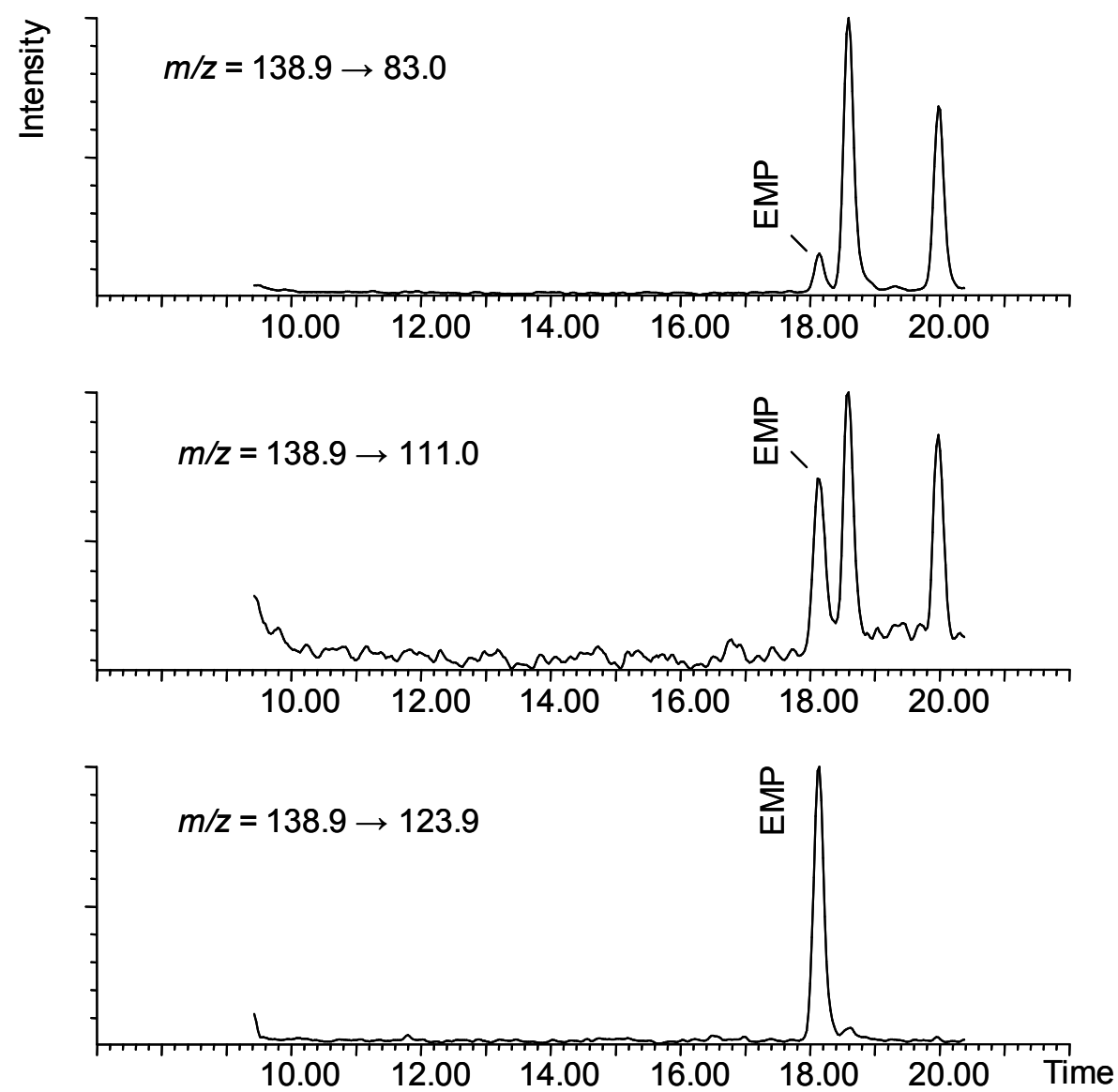

FIGURE 2

MRM chromatograms of three ion transitions obtained for EMP in purified extracts (see Sample preparation) of Sauvignon blanc wine containing 4.9 ng/L EMP utilising LC-APCI-MS/MS (HPLC program B, Chromatographic details). 
injection GC-MS (Lacey et al., 1991), but method detection limits (ranging from 0.5 to $40 \mathrm{ng} / \mathrm{L}$ ) did not allow reliable quantification of this compound. Therefore, apart from a single tentative and unconfirmed report (Allen \& Lacey, 1998), the current contribution represents the first report providing accurate quantitative data as well as spectral confirmation of EMP in wine.

The concentration of EMP in the 10 samples analysed varied between 1.1 and $4.9 \mathrm{ng} / \mathrm{L}$, with an average of $2.9 \mathrm{ng} / \mathrm{L}$ (RSD of $48 \%, n=10$ ). At concentrations of this order of magnitude, EMP is not expected to affect the aroma of these wines, considering that its odour threshold in water is 425 ng/L (Allen \& Lacey, 1998). As is evident from Fig. 3, the concentrations of EMP in these samples generally co-vary with those of the three other MPs (IPMP, IBMP and SBMP). This observation suggests that the synthesis and degradation of these four MPs may be affected by the same variables (Ryona et al., 2010).

\section{Quantitative survey of the three principal 3-alkyl-2- methoxypyrazines in South African Sauvignon blanc wines}

Three MPs (IPMP, IBMP and SBMP) have been found to contribute to the characteristic vegetative aroma of Sauvignon blanc wine (Allen et al., 1991; Lacey et al., 1991; Allen \& Lacey, 1998; Roujou de Boubee et al., 2000; Sala et al., 2002; Marais, 2004; Marais et al., 2004). Although IBMP is invariably dominant, these compounds have similar odour detection thresholds, and their combined concentrations must be considered in the study of their flavour contribution to these wines (Allen \& Lacey, 1998). At a combined concentration of $4 \mathrm{ng} / \mathrm{L}$ to $8 \mathrm{ng} / \mathrm{L}$, the herbaceous or vegetative aroma becomes evident in white wine, while the optimum concentration for Sauvignon blanc wine has been described as $8 \mathrm{ng} / \mathrm{L}$ to $15 \mathrm{ng} / \mathrm{L}$. These levels are often difficult to obtain in warmer climates such as South Africa. Sensory perception at concentrations $>30 \mathrm{ng} / \mathrm{L}$ are considered overpowering and out of balance (Allen \& Lacey, 1998).

In this study, data pertaining to the MP content of South African Sauvignon blanc wines accumulated over four years are reported, comprising a total of 881 samples from all wine-producing regions of South Africa and covering vintages from 1999 to 2011. The IBMP concentration in these samples ranged between 0.40 and $63 \mathrm{ng} / \mathrm{L}$ (RSD of $107.4 \%$, with an average of $7.5 \mathrm{ng} / \mathrm{L}$ and a median of 4.9 ng/L. Table 4 presents a concise summary of the IBMP concentrations of all the wines, over these vintages, grouped according to geographical origin.

The concentrations of IPMP and SBMP varied from below the $\operatorname{LOD}(0.03 \mathrm{ng} / \mathrm{L})$ to $7.5 \mathrm{ng} / \mathrm{L}$ and $3.3 \mathrm{ng} / \mathrm{L}$ respectively, and generally followed similar trends to those observed for IBMP. The ratios of IPMP to IBMP and SBMP to IBMP were approximately $10 \%$ in each case, and these displayed less variation than the overall IBMP concentration. These data follow similar trends compared to our previous study for a smaller set of wines (Alberts et al., 2009). However, the addition of 304 samples spanning a wider range of vintages and extending the representation of geographical origins has improved the statistical representation of the South African Sauvignon blanc industry to increase the validity of conclusions drawn from the data. Furthermore, the malic acid content was determined for a subset of samples, which were used together with general wine parameters to investigate the correlation of these parameters with methoxypyrazine concentrations.

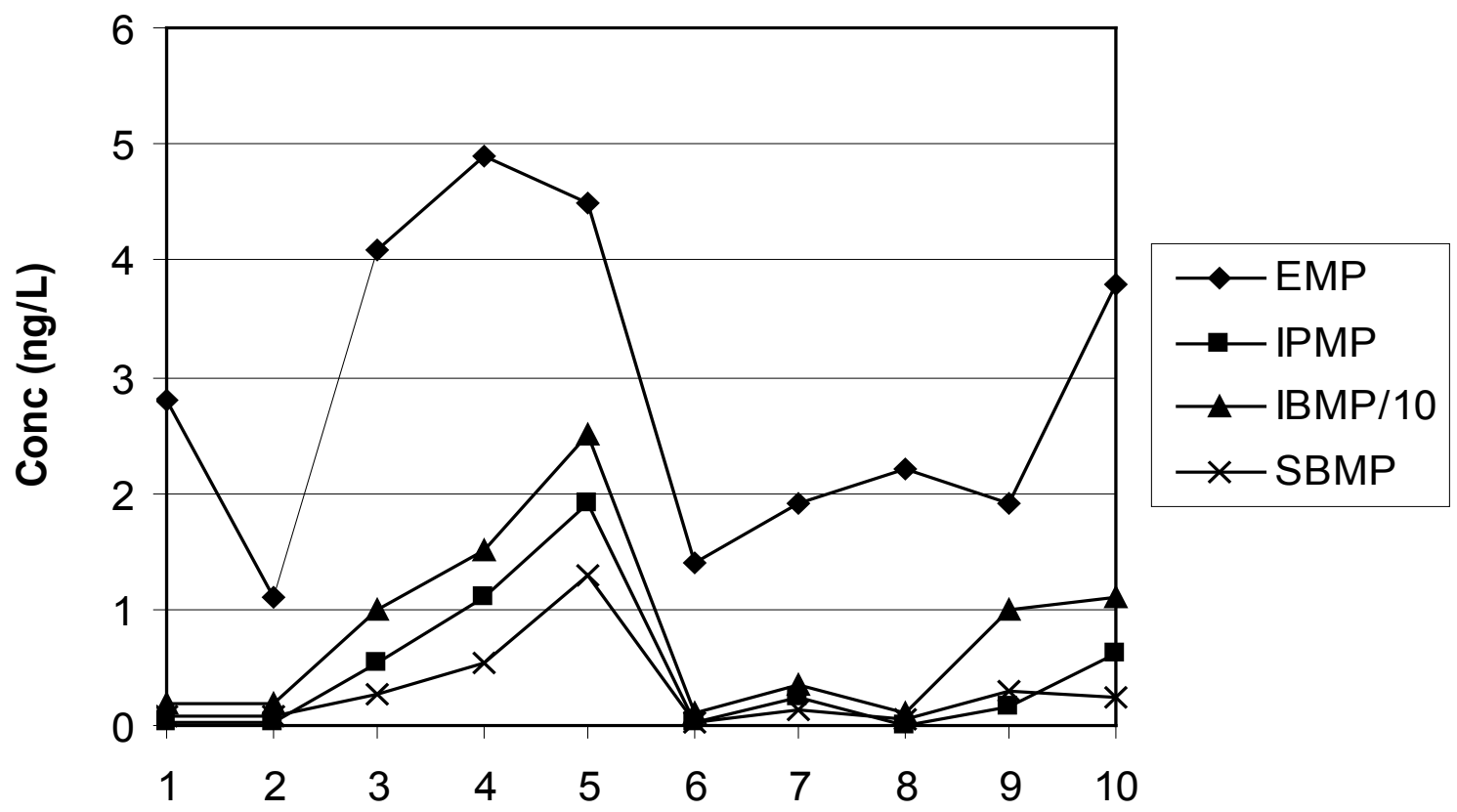

Sample no.

FIGURE 3

Concentrations of four MPs in 10 samples of South African Sauvignon blanc wine. IBMP attenuated (by a factor of 10) to enhance the readability of the figure. 
TABLE 4

IBMP levels (ng/L) in South African Sauvignon blanc wines from different geographical origins over vintages 1999 to 2011.

\begin{tabular}{|c|c|c|c|c|c|}
\hline Region / district / ward & $n$ & Minimum & Maximum & Average & $\%$ RSD \\
\hline Breede River Valley & 152 & 0.60 & 53 & 5.7 & 122.4 \\
\hline - Breedekloof ${ }^{a}$ & 20 & 0.89 & 26 & 8.0 & 81.6 \\
\hline - Robertson ${ }^{a}$ & 81 & 0.63 & 53 & 6.0 & 138.5 \\
\hline - Worcester ${ }^{a}$ & 42 & 0.60 & 17 & 4.7 & 83.2 \\
\hline Coastal Region & 402 & 0.40 & 63 & 8.5 & 100.1 \\
\hline - Cape Point ${ }^{a}$ & 4 & 11 & 62 & 25 & 97.2 \\
\hline - Constantia ${ }^{b}$ & 25 & 6.1 & 29 & 12 & 46.1 \\
\hline - Darling a & 18 & 4.6 & 39 & 14 & 53.7 \\
\hline - Paarl ${ }^{a}$ & 61 & 0.52 & 24 & 4.3 & 123.8 \\
\hline - Tygerberg ${ }^{\text {a }}$ & 33 & 0.74 & 38 & 11 & 74.6 \\
\hline - Stellenbosch ${ }^{\text {a }}$ & 162 & 0.76 & 63 & 7.8 & 113.9 \\
\hline - Swartland ${ }^{\mathrm{a}}$ & 5 & 1.3 & 5.5 & 3.4 & 44.4 \\
\hline - Tulbagh ${ }^{a}$ & 3 & 1.9 & 2.2 & 2.0 & 7.5 \\
\hline Olifants River & 6 & 3.5 & 45 & 17 & 104.6 \\
\hline - Lutzville Valley ${ }^{a}$ & 4 & 4.6 & 45 & 22 & 90.0 \\
\hline Cape Agulhas ${ }^{\text {a }}$ & 18 & 4.2 & 42 & 17 & 65.8 \\
\hline Overberg $^{\text {a }}$ & 22 & 1.3 & 26 & 9.1 & 85.7 \\
\hline Walker bay ${ }^{a}$ & 18 & 1.2 & 25 & 7.2 & 85.4 \\
\hline Cederberg $^{b}$ & 5 & 3.3 & 16 & 10 & 55.2 \\
\hline Prince Albert Valley ${ }^{\mathrm{b}}$ & 3 & 0.81 & 4.2 & 2.0 & 97.8 \\
\hline Little Karoo & 3 & 1.4 & 6.5 & 3.2 & 87.8 \\
\hline Western Cape $^{\mathrm{c}}$ & 250 & 0.48 & 44 & 6.1 & 112.0 \\
\hline
\end{tabular}

${ }^{a}$ District

${ }^{\mathrm{b}}$ Ward

${ }^{c}$ All wine-producing areas of the Western Cape

Two outstanding features in these data are the large variance in (RSD of 108.5\%) and asymmetric distribution of (skewness of distribution around mean $=2.8$ ) the total MP concentration of these samples (where total MP concentration refers to the sum of IBMP, IPMP and SBMP). In Fig. 4, the predicted flavour contribution of the total MPs (based on Allen \& Lacey, 1998) to the analysed South African wines is given as a function of percentage of the total number of samples. It should be noted that, due to synergistic interactions between various aroma compounds, sensory properties and consumer preference of Sauvignon blanc wines are difficult to predict with great precision (Escudero et al., 2007; King et al., 2011), and the flavour descriptions used in the current context refer to the probable effect that these compounds may have on the aroma of the wines. The predicted flavour descriptions range from below recognition through to overpowering and out of balance, with $18 \%$ of the samples falling in the narrow concentration window where their contribution may be regarded as positively favourable to the vegetative Sauvignon blanc wine aroma. The majority of the samples were at the lower end of the scale, with $38 \%$ of the wines classified as below recognition, while in $30 \%$ of the cases the green pepper aroma should be recognisable based on the MP concentrations.
Statistical investigation of the relationship between the viticultural parameters and 3-alkyl-2-methoxypyrazine content of South African Sauvignon blanc wines

In general, the timing of the harvest is a very important viticultural parameter, as wine quality is limited by the properties of the fruit used in the vinification process. During the final stages of maturation, grape sugars and acids undergo important quantitative changes (see further), and the optimal harvest date ultimately depends on the intended style of the final product. At the same time, these parameters are also affected by climatic and viticultural factors (Jackson, 2000). Therefore, wine parameters such as acidity, $\mathrm{pH}$ and alcohol content may reveal information related to factors such as the maturity of the grapes at the time of harvesting, as well as climatic and viticultural conditions. Since wine MP concentrations are also strongly and systematically influenced by these viniviticultural factors, their correlation with wine parameters such as TA, VA, malic acid, $\mathrm{pH}$ and Alc were investigated for a subset $(n=158)$ of wines using two-dimensional and multivariate data analysis techniques. In addition, differences between vintages and regions of origin were elucidated (for the entire dataset, $n=881$ ) using methoxypyrazine data for the three principal congeners in order to assess the effects of annual climatological variations and geographic differences.

Apart from the change in sugar content, the reduction 


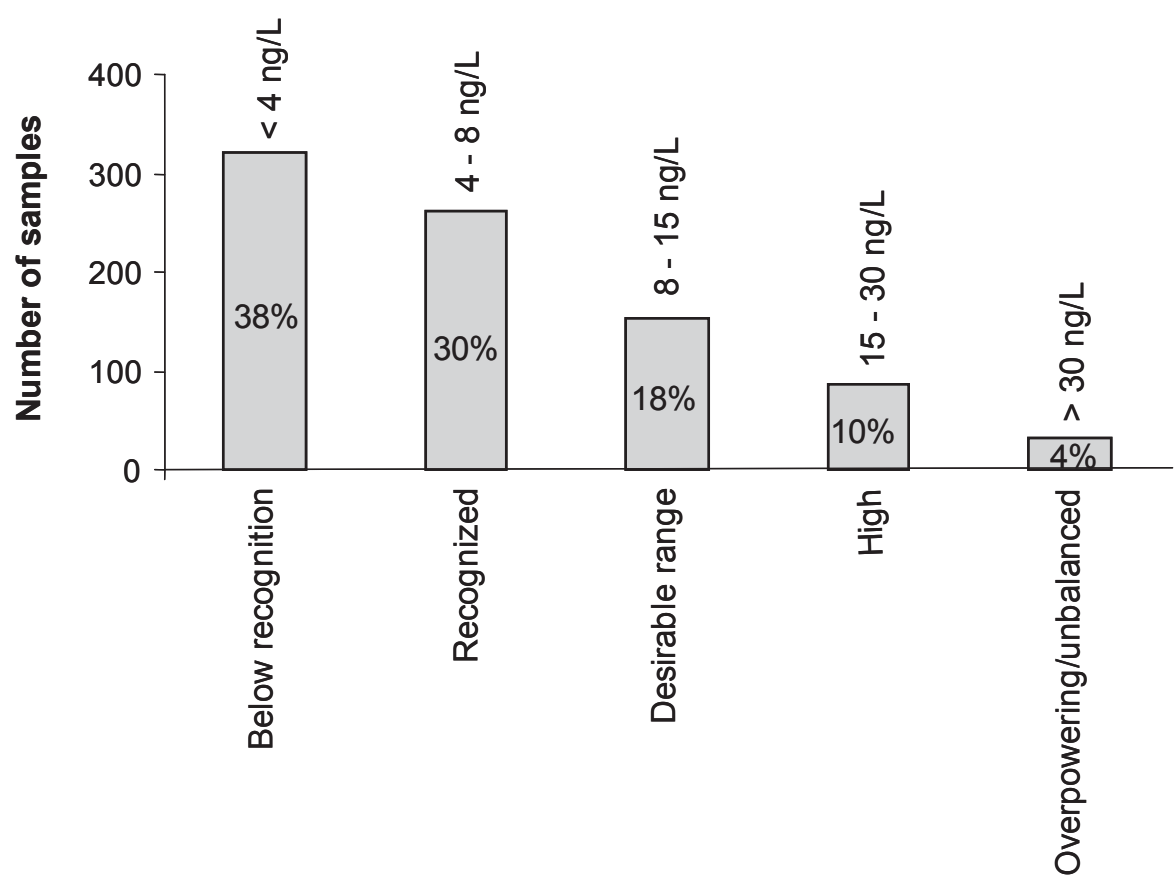

FIGURE 4

The predicted aroma contribution (based on Allen and Lacey, 1998) of total MPs as a function of frequency in 881 South African Sauvignon blanc wines.

of acidity is quantitatively the largest chemical change to occur in grapes during ripening. Tartaric and malic acids are quantitatively the most abundant grape acids, accounting for approximately 70 to $90 \%$ of the berry acid content. The levels of these acids are determined by complex factors, but certain trends are generally observed. While the tartaric acid content remains relatively stable after véraison, the malic acid content of grapes declines drastically during maturation. The rate of decline in berry malic acid is cultivar dependent and is also strongly influenced by environmental factors. It is generally accepted that grapes grown in hot climates often metabolise most of their malic acid before harvest, whereas grapes grown in cooler climates retain most of their malic acid into maturity (Jackson, 2000). As a result, a relatively high wine malic acid concentration may indicate that the grapes were harvested earlier or were grown in cool conditions, both of which are also factors that are associated with higher levels of wine MPs (Hashizume \& Samuta, 1999; Marais et al., 1999; Roujou de Boubee et al., 2000; Marais, 2004; Sala et al., 2004; Ryona et al., 2010). This hypothesis is supported by a study that reported that the breakdown of malic acid and IBMP in grapes during ripening is highly correlated $\left(r^{2}\right.$ of 0.90 to 0.99 ), irrespective of soil type, grape variety or vintage (Roujou de Boubee et al., 2000). The malic acid content of a wine may therefore reveal information regarding cultivation microclimate and maturity of the grapes and, by extension, the methoxypyrazine potential of the product.

In addition, it has also been reported that excessive vigour (the relationship between foliage and fruit) is consistently correlated with reduced acidity and high wine $\mathrm{pH}$ (Jackson, 2000). Vigour, in turn, is also correlated with higher levels of wine MPs, mainly as a result of the shading of bunches during ripening (Marais et al., 1999). Low wine total acidity and high $\mathrm{pH}$, when resulting from increased vigour, may therefore be correlated with higher levels of wine MPs. These phenomena (early harvesting and vigour) are generally associated with higher levels of wine MPs, but they have opposing effects on wine $\mathrm{pH}$ and acidity. However, since the level of tartaric acid is relatively stable after véraison, the ratio of tartaric to malic acid may be more significant in predicting the levels of wine MPs.

These hypotheses were investigated to determine whether the MP content of Sauvignon blanc wines was correlated with wine parameters such as malic acid content, acidity, $\mathrm{pH}$ and alcohol content. Note that reducing sugars are not expected to provide useful information in these analyses, since the practice of sweetening may alter this parameter independent of production conditions.

Two-dimensional plots of wine parameters such as Alc, $\mathrm{pH}, \mathrm{TA}, \mathrm{VA}$ and malic acid $v s$. the total wine MP concentration for the subset of 158 samples produced considerable scattering of data-points. Alc (Pearson correlation coefficient, $r=0.04, p 0.65)$ and $\mathrm{pH}(r=0.05$, $p$ 0.52) did not show significant co-variance with total MP content, whereas statistically significant (although weak) positive correlation was observed between the variables TA $(r=0.29, p<0.01)$, VA $(r=0.30, p<0.01)$ and malic acid $(r=0.34, p<0.01)$ and total wine MP concentration. Samples with high levels of TA, VA and malic acid therefore generally also contained higher levels of MPs, while Alc and $\mathrm{pH}$ displayed little systematic variance as a function of MP concentration. Despite these observations, the low correlation coefficients indicate significant scatter in the data, implying that additional factors also affect these variables.

Nature is multivariate in the sense that particular phenomena, such as wine methoxypyrazine content, usually depend on several factors, such as time of harvest, vigour, solar radiation, canopy microclimate, mesoclimate, as well 
as oenological and viticultural practices. Each of these production factors also affects the general wine parameters, such as Alc, pH, TA, VA and malic acid. The multivariate data analysis technique factor analysis was therefore used to determine whether intrinsic correlations exist between wine MP concentrations and these parameters, since this method is suitable for reducing the dimensionality of data by extracting interpretable factors. By reducing multivariate data to a few sets of factors of physical significance, the visual representation of these relationships is enhanced and meaningful interpretation of the data is facilitated. In this way the underlying correlations and qualitative features in the data can be identified.

In the first instance, parallel analysis was performed on the data subset $(n=158)$, for which malic acid was determined to give an indication of the number of factors underlying the original data. Two factors were identified that explained $60.5 \%$ of the total variance. The loadings plot for these two factors is displayed in Fig. 5. It is evident from this analysis that the concentrations of the three principal wine MPs are highly correlated, and mainly are responsible for the variation described by Factor 1 (F1). This implies that, for wines rich in IBMP, the concentrations of IPMP and SBMP are invariably correspondingly high, and vice versa. This information suggests that their occurrence in wine is regulated by the same viniviticultural variables.

Alc and $\mathrm{pH}$ displayed a negative correlation. These variables showed little co-variance as a function of MP concentration (F1), but rather are associated with the variance described by Factor 2 (F2). Malic acid, TA and VA are to a similar extent also positively correlated with MP concentration, and therefore with the variance described by $\mathrm{F} 1$. Of all the wine parameters, TA shows the highest correlation with wine MPs - a phenomenon that may be explained by noting that relatively early harvesting and cool growing conditions result in higher grape acidity and also are favourable for producing wines containing high levels of MPs. On the other hand, relatively late harvesting and warm growing conditions may produce lower grape acidity and also lower wine MPs. The correlation of malic acid with wine MPs supports this observation, as malic acid retention may be ascribed to early harvesting or cool growing conditions factors that are conducive to high wine MPs. The correlation of malic acid levels with MPs observed here is, however, not as clearly defined as the association reported by Roujou de Boubee et al. (2000).

Acetic acid is the main volatile acid in wine and, in the absence of spoilage, it occurs principally as a by-product of yeast and bacterial metabolism (Jackson, 2000). It has been reported that different yeast strains have an effect on the yield of wine MPs from the juice (Marais, 2004; Pickering et al., 2008). The correlation of VA with MP levels therefore possibly may be ascribed to the effect of different yeast strains on the production of acetic acid and MPs in the wine. This assumption is also supported by the correlation of VA and Alc, since it is well known that different yeast strains cause differences in the production of wine ethanol.

The positive correlation of malic acid content with $\mathrm{pH}$ indicates cool growing conditions, conducive to the retention of grape malic acid into maturity, while simultaneously also leading to low TA and high wine $\mathrm{pH}$. The same phenomenon also explains the negative correlation of malic acid with Alc, as cool growing conditions, which favour malic acid retention, also produce lower levels of sugars and less alcoholic wines. The fact that $\mathrm{pH}$ is not correlated at all with F1 might be due to the opposing effects of vigour (lower acidity) and early harvesting (higher acidity) on wine $\mathrm{pH}$, while both these factors are conducive to higher wine MPs. The negative correlation of $\mathrm{pH}$ and Alc confirms the validity of these assumptions, as cool growing conditions and vigour lead to the production of fewer acids (higher wine $\mathrm{pH}$ ) and lower sugars (lower wine alcohol) at the same time. On the other hand, riper grapes contain higher levels of sugars and lower levels of acids, yielding higher $\mathrm{pH}$ and more alcoholic wines. The fact that this phenomenon (wines with high $\mathrm{pH}$ and high alcohol content) is not observed in this analysis demonstrates the involvement of cool growing conditions and vigour in the production of these wines.

Surprisingly, a positive correlation between Alc and TA was found for the analysed wines. It would be expected that higher acidity, resulting from early harvesting and cool growing conditions, would simultaneously also lead to the production of lower sugars and less alcoholic wines.

From these data it would appear that climactic conditions, grape ripeness and vigour all play a determinative role in the MP content of Sauvignon blanc wines. Furthermore, while general wine parameters such as TA, VA and malic acid concentration show some correlation with MP levels, they are not absolute indicators of the MP content of Sauvignon blanc wines, due to the complex interplay between variables affecting MP concentration in the final wine.

\section{Variations in 3-alkyl-2-methoxypyrazine content of South African Sauvignon blanc wines as a function of geographical origin}

In wine production, certain factors that have an effect on the product are related to its geographical origin. Aspects such as soil influences (for example geological origin, texture, structure, drainage and water availability, depth, nutrient content and $\mathrm{pH}$, organic content and colour), topographic influences (for example solar exposure, wind direction, frost and winter protection, altitude and drainage) and atmospheric influences (such as temperature, solar radiation, wind and water availability) have an impact on the final product to varying extents. This point is amply illustrated by noting that regions affected by continental influences may have more than twice the average day-night temperature variation compared to an equivalent maritime region. In addition, seasonal climatic variations may manifest changes in the product as a function of vintage (Jackson, 2000). In grapes, the concentrations of MPs are strongly influenced by terroir (soil, climatic and viniviticultural influences) (Lacey et al., 1991; Allen \& Lacey, 1998; Hashizume \& Samuta, 1999; Marais et al., 1999; Roujou de Boubee et al., 2000; Marais et al., 2004; Sala et al., 2004, 2005; Maggu et al., 2007). The systematic effect of geographical origin and vintage on the total MP concentration of South African Sauvignon blanc wines therefore was investigated using main effects ANOVA.

Firstly, classification according to region of origin was 
Factor Loadings, Factor 1 vs. Factor 2

Rotation: Varimax normalized

Extraction: Principal components

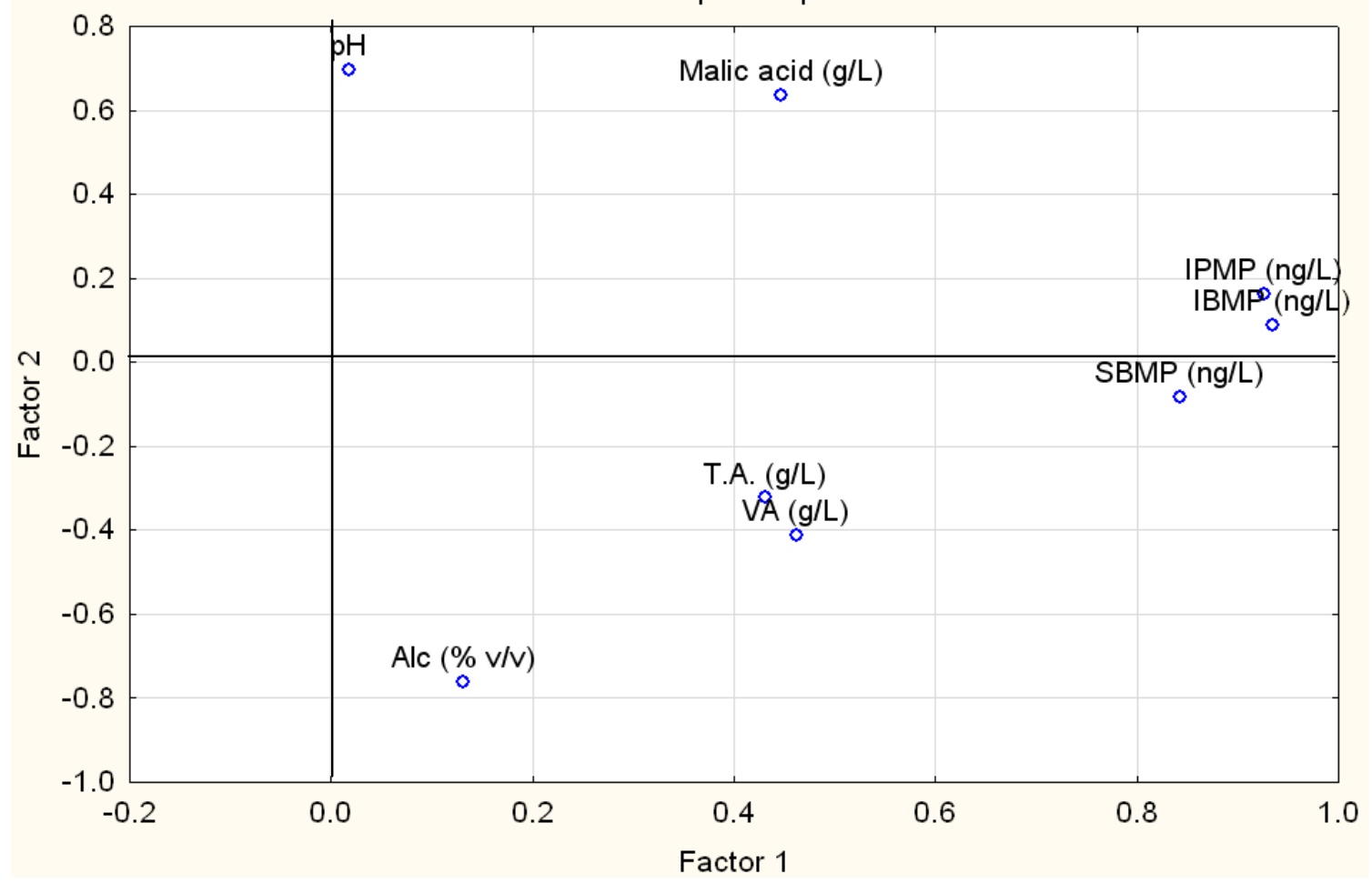

FIGURE 5

Loadings plot for factor analysis of two principal factors explaining 38.2 and $22.3 \%$ of the total variance respectively, obtained for the data subset of 158 wines.

investigated. In the South African wine of origin scheme, wines may be certified for region of origin by classification into regions, districts or wards (see Table 4). Of these categories, region is the broadest category of classification. Samples from all vintages in the dataset were therefore grouped according to region, where appropriate, while all non-specific origins (such as Western Cape) and minor regions (for which insufficient data were available) were removed. A data subset of 554 samples was obtained, of which 145 samples originated from the Breede River Valley and 385 samples from the Coastal Region. This subset was analysed by ANOVA to determine whether these origins can be distinguished based on the total MP concentration of these wines. The mean of the Breede River Valley group $(6.15 \mathrm{ng} / \mathrm{L})$ was lower than that of Coastal Region $(9.17 \mathrm{ng} / \mathrm{L}, p<0.01)$. This result possibly indicates slightly warmer growing conditions prevalent in the Breede River Valley compared to the Coastal Region. Despite the relatively wide limits for the $95 \%$ confidence interval, which indicate significant variation in MP levels, statistically significant differences in mean values were found between these two regions.

ANOVA was subsequently used to elucidate grouping of samples from different districts located in the greater Breede River Valley and Coastal Region respectively, using total MP data. By performing main effects ANOVA using wine samples for those districts that are represented by a statistically significant number of samples and over vintages 2003 to 2011, significant differences between these districts were elucidated, and in this way the effect of variation over vintages was taken into account. Fig. 6A illustrates that there are clear differences between some districts in terms of total wine MP content. For example, Overberg and Tygerberg were clearly distinct from Paarl and Robertson, based on higher levels of MPs. Overberg and Tygerberg are two districts located in relative close proximity to the Atlantic Ocean, and this result possibly indicates favourable viniviticultural conditions for Sauvignon blanc production in these locations. On the other hand, this analysis indicates that Paarl and Robertson represent districts that are characterised by warmer climates and generally produce wines that contain lower levels of MPs. Since this analysis represents a large number of samples $(n=382)$ and is independent of vintage, it is clear that statistically significant differences $(p<0.01)$ exist in wine MP levels between different districts. This shows that certain districts inherently lend themselves to the production of Sauvignon blanc wines of higher MP content. This observation is in agreement with the work of Marais et al. (1999), who also observed the suitability of distinct localities for Sauvignon blanc production.

Note that discrepancies in the number of samples between the districts, as well as variance in the data for each district, affect the results reported in Fig. 6A. For example, Stellenbosch represents the largest number of samples $(n=$ $158)$, while Overberg $(n=20)$ is represented by much lower numbers, which explains the larger $95 \%$ confidence interval for the latter. As before, these significant differences cannot be used to classify wines absolutely according to districts of origin, due to the relatively large variation in each group. 


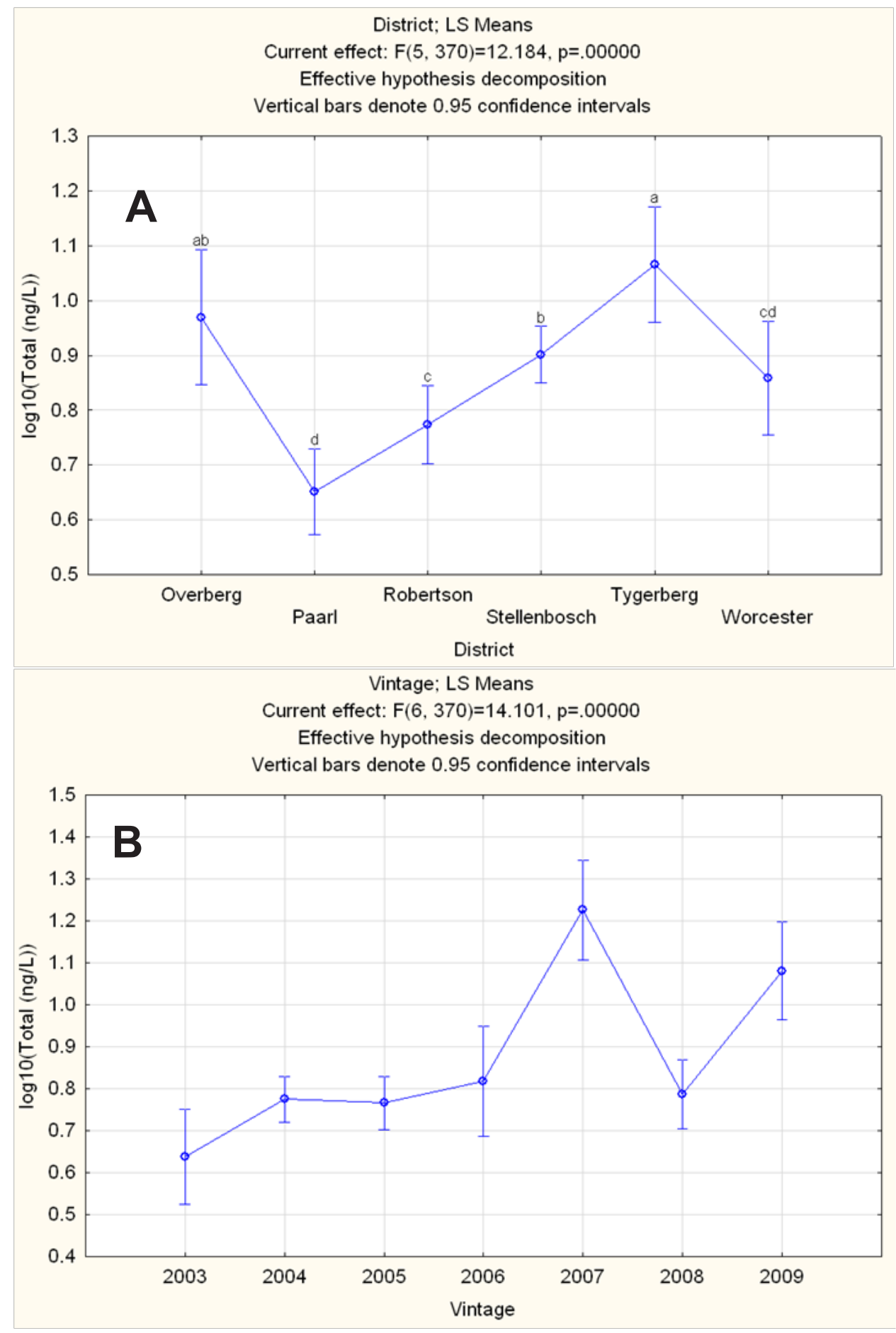

FIGURE 6

ANOVA results for determining significant differences between (A) districts and (B) vintages between 2003 and 2009, based on total wine methoxypyrazine concentration.

Variation in 3-alkyl-2-methoxypyrazine content of South African Sauvignon blanc wines as a function of vintage The effect of climatic variations on total wine MP concentration was evaluated by comparing mean MP levels in the total dataset between vintages. Samples from 2003 to 2009 ( $n=382)$ were compared, controlling for district in a main effects ANOVA. From the information in Fig. 6B, it is clear that wines with relatively high levels of MPs were produced in 2007 and 2009. Since the data are independent of geographical origin, this result suggests that favourable climatological conditions (such as lower temperatures, higher rainfall and/or lower solar radiation) were prevalent in the 2007 and 2009 seasons compared to other vintages. It should be noted that ageing had no measurable effect on methoxypyrazine concentrations for bottled wines, as confirmed by the analysis of the same wines in consecutive years.

Finally, it should be noted that the commercial products analysed in this study, although labelled as single varietal wines, may contain between 15 and $25 \%$ of other varieties 
(depending on vintage). In addition, wines certified for vintage may contain up to $15 \%$ of wine from the preceding or subsequent years (Liquor Products Act, 1989). This additional variability can certainly contribute to the observed variance in MP concentrations, particularly considering that the grapevine synthesis of MPs is highly dependent on genotype (Koch et al., 2010), and because of climatic variations between vintages (Lacey et al., 1991; Falcăo et al., 2007).

\section{CONCLUSION}

In this study, an LC-APCI-MS/MS method was applied to generate the first extensive database of the levels of 3-alkyl2-methoxypyrazines in 881 samples of South African Sauvignon blanc wines spanning 13 vintages and all the major wine-producing regions of the country. The total MP concentration (sum of IPMP, IBMP and SBMP) in these samples ranged from 0.52 to $72 \mathrm{ng} / \mathrm{L}$, suggesting that the typical green pepper aroma of these products may range from below recognition through to overpowering and out of balance. Their combined concentrations exceeded the recognition threshold for the vegetative aroma in more than $60 \%$ of the samples analysed, demonstrating the extent of involvement of these compounds in the typical aroma of the cultivar.

The first confirmation of 3-ethyl-2-methoxypyrazine in Sauvignon blanc wines is reported, and this compound was accurately quantified in a subset of 10 samples using modified extraction and analysis procedures. The concentrations of 3-ethyl-2-methoxypyrazine were two orders of magnitude below its odour detection threshold, which makes it highly unlikely that this methoxypyrazine contributes significantly to the aroma of these wines.

Statistical analysis of the total MP content data using factor analysis shows that the concentrations of IPMP, IBMP and SBMP are highly correlated, suggesting that their occurrence in Sauvignon blanc wines is regulated by the same factors. In addition, factor analysis revealed that methoxypyrazines are correlated with total acidity, volatile acids and malic acid. Higher acidity may result from earlier harvesting, while higher levels of malic acid in particular indicate cooler climates or early harvesting, viniviticultural conditions that are also favourable for the production of wines containing higher levels of MPs. The observed correlation between MP levels and volatile acids could possibly be ascribed to the effect of different yeast strains on the yield of MPs from the juice. Statistical analysis using ANOVA showed significant differences between wines from different geographical origins (independent of vintage) and vintages (independent of geographical origin). The Overberg and Tygerberg districts appear to be particularly suited for the production of varietal-typical vegetative Sauvignon blanc wines, as they displayed higher average total MP concentrations, while the 2007 and 2009 vintages also produced wines that contained higher average levels of MPs across all regions. The data presented in this paper sheds much-needed light on the MP content of representative South African Sauvignon blanc wines and the factors affecting the levels of these influential aroma compounds.

\section{LITERATURE CITED}

Alberts, P., Stander, M.A. \& De Villiers, A., 2009. Survey of 3-alkyl-2methoxypyrazine content of South African Sauvignon blanc wines using a novel LC-APCI-MS/MS method. J. Agric. Food Chem. 57, 9347-9355.

Allen, M.S. \& Lacey, M.J., 1998. Chemistry of wine flavor. Oxford University Press, New York.

Allen, M.S., Lacey, M.J., Harris, R.L.N. \& Brown, W.V., 1991. Contribution of methoxypyrazines to Sauvignon blanc wine aroma. Am. J. Enol. Vitic. 42, 109-112.

Augustyn, O.P.H., Rapp, A. \& Van Wyk, C.J., 1982. Some volatile aroma components of Vitis vinifera L. cv. Sauvignon blanc. S. Afr. J. Enol. Vitic. 3, 53-60.

Blake, A., Kotseridis, Y., Brindle, I.D., Inglis, D., Sears, M. \& Pickering, G.J., 2009. Effect of closure and packaging type on 3-alkyl-2-methoxypyrazines and other impact odorants of Riesling and Cabernet Franc wines. J. Agric. Food Chem. 57, 4680-4690.

Escudero, A., Campo, E., Farina, L., Cacho, J. \& Ferreira, V., 2007. Analytical characterization of the aroma of five premium red wines. Insights into the role of odor families and the concept of fruitiness of wines. J. Agric. Food Chem. 55, 4501-4510.

Falcăo, L.D., De Revel, G., Perello, M.C., Moutsiou, A., Zanus, M.C. \& Bordignon-Luiz, M.T., 2007. A survey of seasonal temperatures and vineyard altitude influences on 2-methoxy-3-isobutylpyrazine, $\mathrm{C}_{13}$ norisoprenoids, and the sensory profile of Brazilian Cabernet Sauvignon wines. J. Agric. Food Chem. 55, 3605-3612.

Galvan, T.L., Kells, S., Hutchison, W.D., 2008. Determination of 3-alkyl-2-methoxypyrazines in lady beetle-infested wine by solid-phase microextraction headspace sampling. J. Agric. Food Chem. 56, 1065-1071.

Godelmann, R., Limmert, S. \& Kuballa, T., 2008. Implementation of headspace solid-phase-microextraction-GC-MS/MS methodology for determination of 3-alkyl-2-methoxypyrazines in wine. Eur. Food Res. Technol. 227, 449-461.

Hashizume, K. \& Samuta, T., 1999. Grape maturity and light exposure affect berry methoxypyrazine concentration. Am. J. Enol. Vitic. 50, 194-198.

Jackson, R.S., 2000 ( $2^{\text {nd }}$ ed). Wine science: Principles, practice and perception. Academic Press, San Diego.

King, E.S., Osidacz P., Curtin C., Bastian S.E.P. \& Francis I.L., 2011 Assessing desirable levels of sensory properties in Sauvignon blanc wines consumer preferences and contribution of key aroma compounds. Austr. J. Grape Wine Res. 17, 169-180.

Koch, A., Doyle, C.L., Matthews, M.A., Williams, L.E. \& Ebeler, S.E., 2010. 2-Methoxy-3-isobytylpyrazine in grape berries and its dependence on genotype. Phytochemistry 71, 2190-2198.

Lacey, M.J., Allen, M.S., Harris, R.L.N. \& Brown, W.V., 1991 Methoxypyrazines in Sauvignon blanc grapes and wines. Am. J. Enol. Vitic. 42, 103-108.

Liquor Products Act, Act 60, 1989, Government Gazette, Republic of South Africa, Pretoria.

Maga, J.A. \& Sizer, C.E., 1973. Pyrazines in food. A review. J. Agric. Food Chem. 21, 22-30.

Maggu M., Winz R., Kilmartin P.A., Trought, M.C.T. \& Nicolau L., 2007. Effect of skin contact and pressure on the composition of Sauvignon blanc must. J. Agric. Food Chem. 55, 10281-10288.

Marais, J., 2004. Factors affecting Sauvignon blanc wine quality: a South African perspective. Wynboer 12,69-70. 
Marais, J., Hunter J.J. \& Haasbroek, P.D., 1999. Effect of canopy microclimate, season and region on Sauvignon blanc grape composition and wine quality. S. Afr. J. Enol. Vitic. 20, 19-30.

Marais, J., Minnaar, P. \& October, F., 2004. 2-Methoxy-3-isobutylpyrazine levels in a spectrum of South African Sauvignon blanc wines. Wynboer.

Murray, K.E. \& Whitfield, F.B., 1975. The occurrence of 3-alkyl-2methoxypyrazines in raw vegetables. J. Sci. Food Agric. 26, 973-986.

O’Keeffe, M.J., Martin, S. \& Regan, L., 2003. Validation of a multiresidue liquid chromatography-tandem mass spectrometric method for the quantitation and confirmation of corticosteroid residues in urine, according to the proposed SANCO 1085 criteria for banned substances. Anal. Chim. Acta 483, 341-350.

Pickering, G.J., Spink, M., Kotseridis, Y., Inglis, D., Brindle, I.D., Sears, M. \& Beh, A.-L., 2008. Yeast strain affects 3-isopropyl-2-methoxypyrazine concentration and sensory profile in Cabernet Sauvignon wine. Austr. J. Grape Wine Res. 14, 230-237.

Roujou de Boubee, D., Van Leeuwen, C. \& Dubourdieu, D., 2000. Organoleptic impact of 2-methoxy-3-isobutylpyrazine on red Bordeaux and Loire wines, effect of environmental conditions on concentrations in grapes during ripening. J. Agric. Food Chem. 48, 4830-4834.

Ryona, I., Leclerc, S. \& Sacks, G.L., 2010. Correlation of 3-isobutyl-2methoxypyrazine to 3-isobutyl-2-hydroxypyrazine during maturation of bell pepper (Capsicum annuum) and wine grapes (Vitis vinifera). J. Agric. Food Chem. 58, 9723-9730.
Sala, C., Busto, O., Guasch, J. \& Zamora, F., 2004. Influence of vine training and sunlight exposure on the 3-alkyl-2-methoxypyrazines content in musts and wines from the Vitis vinifera variety Cabernet Sauvignon. J. Agric. Food Chem. 52, 3492-3497.

Sala, C., Busto, O., Guasch, J. \& Zamora, F., 2005. Contents of 3-alkyl-2methoxypyrazines in musts and wines from Vitis vinifera variety Cabernet Sauvignon: influence of irrigation and plantation density. J. Sci. Food Agric. $85,1131-1136$

Sala, C., Mestres, M., Marti, M.P., Busto, O. \& Guasch, J., 2000. Headspace solid-phase microextraction method for determining 3-alkyl2-methoxypyrazines in musts by means of polydimethylsiloxanedivinylbenzene fibres. J. Chromatogr. A 880, 93-99.

Sala, C., Mestres, M., Marti, M.P., Busto, O. \& Guasch, J., 2002. Headspace solid-phase microextraction analysis of 3-alkyl-2-methoxypyrazines in wines. J. Chromatogr. A 953, 1-6.

Schmarr, H.-G., Ganß, S., Koschinski, S., Fischer, U., Riehle, C., Kinnart, J., Potouridis, T. \& Kutyrev, M., 2010. Pitfalls encountered during quantitative determination of 3-alkyl-2-methoxypyrazines in grape must and wine using gas chromatography-mass spectrometry with stable isotope dilution analysis. Comprehensive two-dimensional gas chromatography-mass spectrometry and on-line liquid chromatography-multidimensional gas chromatography-mass spectrometry as potential loopholes. J. Chromatogr. A $1217,6769-6777$.

Skoog, D.A., West, D.M. \& Holler, F.J., 1996 ( $7^{\text {th }}$ ed). Fundamentals of analytical chemistry. Saunders College Publishing, Orlando. pp. 660 - 724. 